\section{How Social Support Motivates Trust and Purchase Intentions in Mobile Social Commerce}

\author{
Yong Liu ${ }^{1}$ \\ Xiaowei Su${ }^{1}$ \\ Xiaojing Du ${ }^{1}$ \\ ${ }^{1}$ Chengdu University of Technology, College of \\ Management Science, Chengdu, China \\ Fu Cui ${ }^{2}$ \\ ${ }^{2}$ Xiangtan University, School of Business, Xiangtan, Hunan, China
}

\begin{abstract}
Purpose - This study refers to the social support and trust theories to explore what kind of factors affect the users' intention to adopt MSC.

Design/methodology/approach - A total of 207 subjects who had previously experienced or known about MSC were identified and partial least squares were performed to analyse the measurement and structural models.
\end{abstract}

Findings - The results indicated that MSC purchase intentions are affected significantly by four other factors (social support, perceived usefulness, subjective norm, and trust) and trust, in turn, is affected by three factors (social support, perceived usefulness, and subjective norms).

Originality/value - First, this study examines the mechanism of trust formation and actions in the MSC context. Second, this study contributes by confirming the important role of social factors in the MSC context. Third, the study expands the social support theory. Finally, our research provides empirical evidence for enterprises that have adopted MSC to support their marketing strategy and programmes.

Keywords - Mobile social commerce, Social support, Trust, Purchase intention
Received on

9/11/2018

Approved on

01/22/2019

\section{Responsible editor:}

Dr. Prof. Francisco Liébana-

Cabanillas

\section{Evaluation process:}

Double Blind Review

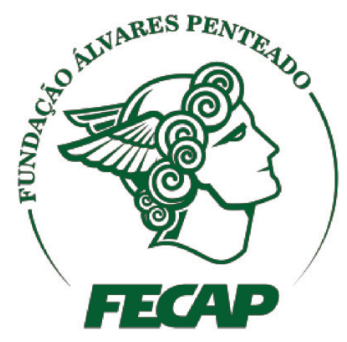

Review of Business Management 


\section{Introduction}

Following the proliferation of $3 \mathrm{G} / 4 \mathrm{G}$ and Wi-Fi technologies, mobile social media such as WeChat and Sina Weibo have become increasingly popular among users today. According to a report issued by the China Internet Network Information Center (CNNIC) in August 2018, the number of mobile social media users has exceeded 755 million, accounting for 94.3 percent of its mobile internet population (802 million) (CNNIC, 2018). Users employ mobile social media for a variety of purposes, such as instant social interaction or the development of a friend network, focusing on interesting people or news, mobile videos and music, information sharing and online shopping (Kaplan, 2012). The online shopping activities which are mediated by social media are called social commerce (Curty $\&$ Zhang, 2013; Liang, Ho, Li, \& Turban, 2011). Social commerce (SC) is a new point of sale. According to survey data from iMedia Research, China Mobile's shopping market will reach 5.7 trillion yuan in 2018, while mobile e-commerce users are expected to exceed 500 million, an increase of 512 million (iMedia Research, 2017). Thus SC has attracted substantial attention from scholars and practitioners (Bai, Yao, \& Dou, 2015; Hajli, 2014a, 2014b; Liang et al., 2011; Zhang, Benyoucef, \& Zhao, 2016; Zhou, Zhang, \& Zimmermann, 2013).

Similar to SC, mobile social commerce (MSC) refers to business activities that are mediated by mobile social media (Kucukcay \& Benyoucef, 2014). Besides having most of the advantages and characteristics of SC, MSC has the significant quality of ubiquity, which implies that customers can use smart phones and other mobile devices to conduct MSC activities via mobile social media without any temporal or spatial limitations (Chang, Witteloostuijn, \& Eden, 2010; Giovannini, Ferreira, Silva, \& Ferreira, 2015; Zhou, 2014b). With the growing popularity of mobile social media, MSC has received considerable interest from commercial enterprises (iMedia Research, 2017). Some companies have recognised the significance of online shopping and integrated commercial features with their mobile social media to develop MSC (Kang \& Johnson, 2015). For example, Tencent, which is the largest social media company in China, has added a public number on WeChat. Sina, a leading social content service provider, has designed a brand page on Weibo. Service providers have invested considerable effort and resources in developing MSC. If they cannot attract users, they will not offset costs and make a profit (Zhou \& $\mathrm{Li}, 2014$ ). Thus it is important to research the factors that influence the customers' acceptance of MSC and such research can help companies to develop and improve their social media marketing strategies.

Previous studies have indicated that trust in the online context is a crucial antecedent of consumers' acceptance of information systems (IS) such as electronic commerce, online payment and SC (Kim \& Park, 2013; Shi \& Chow, 2015; Zhou, 2014a). They have argued that trust has a positive effect on consumers' intentions to use IS. However, they have seldom examined the effect of trust on users' intentions in the MSC environment. MSC is a novel form of IS for most users and, lacking trust and usage experience, these users may perceive great uncertainty and risk when they consider using MSC. This may prevent users from accepting MSC. Jarvenpaa (1999) argued that social media companies cannot fully exploit their economic potential if they are unable to gain the trust of consumers. Therefore, building users' trust is critical to their usage behaviour and it is necessary to examine the effect of trust on users' MSC intentions (Jarvenpaa, 1999).

Extant studies have implied that users' trust may not only be affected by perception-based factors (such as effort expectancy, personal traits or trust propensity), but also by transferencebased factors (such as structural assurance, offline trust and online trust) (Giovannini et al. 2015; Gu \& Xu, 2015; Zhou, 2014a). Giovannini et al. (2015) argued that online trust, offline trust, 
and ease-of-use have positive effects on trust in mobile commerce. Gu and Xu (2015) argued that trust propensity has significant effects on trust in wearable commerce. Zhou (2014a) contended that structural assurance and online trust positively affect trust in mobile payments. Nevertheless, very few studies have investigated the effect of social factors on trust in the MSC context. Compared to other forms of electronic commerce, ubiquitous social interaction is the most significant quality of MSC. Users of MSC interact with their friends and peers via mobile social media anytime and anywhere, searching for products, viewing others' opinions, sharing shopping experiences, seeing product-related information generated by others, discussing prices and recommending products after use (Kang \& Johnson, 2015; Kim \& Park, 2013; Shi \& Chow, 2015). The information generated through online social activities is useful for consumers in making purchasing decisions. These social interactions are important for consumers in building trust in MSC and have a positive effect on their shopping intentions and behaviour (Hajli, 2014a; Liang et al., 2011). Thus, it is important to examine the effect of social factors in the MSC context.

In this research, we propose a theory-based model for investigating the effect of social factors (including social support and subjective norms) and perceived usefulness on customers' trust and intentions in the MSC context. Since the study scrutinises the influencing effect of social factors on MSC acceptance, social factors such as social support and subjective norms are considered as variables. In addition, because user-generated content in social media is useful for consumers in making purchasing decisions, perceived usefulness can be regarded as the outcome variable of social support. Therefore, perceived usefulness is also integrated into the research model. Our study intends to answer these questions: (1) Does social support affect subjective norms, perceived usefulness, and trust in MSC? (2) Do subjective norms and perceived usefulness affect users' trust? (3) Do subjective norms, perceived usefulness, and trust influence users' intentions to use MSC?
The remainder of this article is arranged as follows. First, the theoretical background regarding MSC user behaviour is presented. Second, our research model and hypotheses are described. Next, the research methodology and the results are presented. Finally, we discuss the implications of the findings and suggest directions for future research.

\section{Theoretical Background and Literature Review}

\section{I Mobile social commerce}

Social commerce is a new development in e-commerce and many scholars have carried out research on this topic (Curty \& Zhang, 2011; Gibreel, AlOtaibi, \& Altmann, 2018; Kim \& Park, 2013). Social commerce can be defined as word-of-mouth in e-commerce (Dennison, Bourdagebraun, \& Chetuparambi, 2009) or as taking advantage of relationships in a social network to gain commercial benefits (Liang et al., 2011). With the wide application of wireless communication technology and the popularity of mobile phones, mobile social commerce is gradually increasing. MSC is defined as 'a set of e-commerce activities performed in a mobile environment and enhanced by user-generated content'. This phenomenon is shaping a new model of e-commerce characterised by the commercial society (Liang et al., 2011). Mobile social commerce covers a wide range of business activities which are not only used for transaction purposes, but also for other purposes such as marketing and promotion (Hew, Lee, Ooi, \& Lin, 2016). The popularity of mobile social media opens up a new platform for business and research opportunities.

Existing online shopping research examines how social support, trust, or social commerce constructs can affect the intention of consumers to use social commerce. For example, from the perspective of social support, Liang et al. (2011) studied the influence of social support on the quality of relationships by constructing 
a second-order model of social support, which in turn affected the willingness of mobile social business users to purchase the technology. Bai et al. (2015) investigated the impact of social support on products and sellers' uncertainty, which in turn affect the users' purchasing behaviour. From the perspective of social commerce constructs, Hajli (2013) proposed a theoretical framework for social commerce drawing on social support theory and social commerce constructs, which focused on forums and communities, ratings and reviews, and recommendations and referrals. Hajli (2015) studied how social commerce constructs influenced trust, which in turn affected the purchase intentions of the users. Chen and Shen (2015) investigated social commerce from two different, interrelated perspectives (i.e., social shopping and social sharing) and their study demonstrated that both emotional and informational social support significantly affected consumers' trust. Some studies have focused on traditional e-commerce sites with their own integrated social tools and identified the antecedents of social commerce intentions for traditional e-commerce sites where social tools have been integrated. The results indicated that emotional social support has a positive and direct influence on social commerce intentions (Molinillo, Liébana-Cabanillas, \& AnayaSánchez, 2018). Sheikh, Islam, Rana, Hameed and Saeed (2017) examined online purchase intentions in relation to social media websites in Saudi Arabia and the results revealed that social support has a positive association with behavioural intentions. From the perspective of trust, Hajli (2017) studied the effect of trust on buying intentions on social networking sites. Some scholars found that familiarity and trust play a major role in mediating exchanges between sellers and buyers and have a positive effect on buyers' perceived usefulness of a social commerce platform (Gibreel et al., 2018). Cheng, Gu and Shen (2019) discussed two types of trust (i.e., particularised trust and system trust) that promote trust formation in social commerce. Some studies have applied a stimulus-organism-response model to investigate the influence of social commerce sites on customers' virtual experiences and on their intentions to purchase products. They found that social support influences the intention to trust product recommendations and trust exerted a positive and significant effect on social shopping intentions ( $\mathrm{Li}, 2017)$. Lu (2016) theorised the nature of the social aspects of the online SC marketplace by proposing a set of three social presence variables that have a positive impact on trusting beliefs, which in turn result in online purchasing behaviours. Some studies have investigated the drivers for social commerce on social media platforms and found that trust, social support and the platform's perceived usefulness are important (Cheng et al., 2019).

Although these studies have provided useful insights regarding SC, it is unclear whether these factors have the same effect on MSC. Thus, it is necessary to examine the factors associated with MSC. Although scholars believe that trust has an influence on SC intentions, the formation mechanism of trust is not clear. Previous literature has confirmed that social support has a significant impact on SC intentions, but whether social support can enhance user trust is unknown in the MSC context. Whether emotional support and informational support are useful to consumers also needs to be studied further. In addition, the role of social factors in social commerce and how they generate user trust also need further research. Thus, this study aims to fill important research gaps and propose a comprehensive research model in order to understand users' behaviour in the MSC context.

\subsection{Social support}

Social support is defined as the social resources that people perceive to be available or that are actually provided to them by nonprofessionals in the context of both formal support groups and informal helping relationships (Gottlieb \& Bergen, 2010). Social support is a multidimensional construct involving both 
informational support and emotional support (Bo, 2008; Huang, Nambisan, \& Uzuner, 2010; Madjar, 2011; Ridings \& Gefen, 2004). Informational support refers to providing messages, in the form of recommendations, advice, or knowledge, which could be helpful for solving problems. Emotional support refers to sending messages that convey emotional concern, such as caring, understanding, or empathising (House, 1981; Taylor et al., 2004). Frequent sharing of supportive information can enhance trust between friends and network members, which may further increase the influence of other constructs. Social support, a theory drawn from the social psychology discipline, is attracting the attention of business researchers due to the emergence of Web 2.0. Studies have found that online communities can bring social value to their users. The internet is a powerful tool for individuals to establish intimate relationships with others and to enhance their personal happiness (Bo, 2008; Eastin \& Larose, 2005; Obst \& Stafurik, 2010; Shaw \& Gant, 2002). Social support has been regarded as the main social value that internet users obtain from the online community (Huang et al., 2010; Obst \& Stafurik, 2010; Shaw \& Gant, 2002). Such support, as a kind of enthusiastic feedback, can help a person feel better even if the support does not provide direct assistance in solving the person's problem (Liang et al., 2011).

Liang et al. (2011) used social support theory to demonstrate that social support has positive effects on relationship quality, which in turn affects the intention to continue using the website and the intention to conduct social commerce. Hajli (2015) adopted social commerce constructs and social support theory along with information systems concepts to investigate how the social interaction of individuals, facilitated by social media, affects users' social commerce intentions after sharing and receiving information related to products and services. Therefore, social support theory is appropriate in this case for evaluating the acceptance of mobile social commerce by its users. In addition, social support was generally used as a second-order variable of emotional support and information support (Hajli, 2014a; Liang et al., 2011). Therefore, a second-order social support model is employed to explore the relationships between variables in this study.

\section{$2 \cdot 3$ Trust}

Many researchers have argued that trust is a key element in the online environment (Mutz, 2005; Paul, 2003; Straub, Boudreau, \& Gefen, 2004). Trust has become one of the most widely studied forms of public opinion in the world (Paxton, 1999; Warren \& Abbott, 1999). It has emerged as a theme of research in recent decades because of an interdependent and increasingly globalised world (Cook, 2001). Trust is believed to be important because it reduces the 'transaction costs' involved in interacting with others (Mutz, 2005).

The definitions of trust vary depending on the different dimensions involved. Ba and Pavlou (2002) posited that trust is an individual's belief that an exchange will occur in a manner consistent with their confident expectations. In online contexts, trust is based on beliefs in the trustworthiness of an exchange party (Mcknight, Choudhury, \& Kacmar, 2002). According to Lin (2011), trustworthiness is related to perceptions of competence, benevolence and integrity. The present study defines trust in the sense of trusting belief, referring to the belief that 'one can rely upon a promise made by another and that the other, in unforeseen circumstances, will act toward oneself with goodwill and in a benign fashion' (Suh \& Han, 2003).

Hajli (2015) examined social commerce constructs and their influence on intentions to buy and trust. The findings showed that trust has a positive effect on the intention to buy. Hajli (2013) adopted technology acceptance model (TAM) constructs and proposed a model showing that trust is likely to influence consumer behaviour. Chen and Shen (2015) found that 
individuals have a tendency to seek advice from online communities and members whom they trust to provide correct information regarding their experience of purchasing a product or using an online service. Therefore, trust is a vital component of online shopping environments.

\subsection{Perceived usefulness}

TAM, as proposed by Davis (1989) to analyse and explain individuals' acceptance behaviour for information technology, is derived from the notion of the theory of reasoned action (TRA) (Hill, 1975). TAM argues that the adoption of a new technology depends on two belief variables: perceived usefulness and perceived ease of use. Perceived usefulness is defined as 'the degree to which a person perceives that adopting the system will boost his or her job performance' (Davis, 1989) and perceived ease of use is defined as 'the degree to which a person believes that adopting the system will be free of effort' (Davis, 1989). Perceived usefulness has a direct effect on adoption intentions, while perceived ease of use has both an immediate and an indirect effect on adoption intentions (Davis, 1989). TAM argues that perceived usefulness is a key construct for examining the acceptance of a new information system (Davis, 1989). Some scholars have also employed perceived usefulness as a factor to test users' behaviours in various IS fields (Dutot, 2015; Kim, Mirusmonov, \& Lee, 2010; Tan, Ooi, Chong, \& Hew, 2014). Because MSC is a new information system, it is appropriate to employ perceived usefulness to explore users' MSC behaviour in this study.

\subsection{Subjective norms}

The three central constructs that make up the theory of planned behaviour (TPB) for predicting human intentions and behaviour are attitude, subjective norms and perceived behavioural control (Brown, Venkatesh, \& Bala, 2005). Subjective norms represent the social influences on an individual's engagement in a particular behaviour (Fishbein \& Ajzen, 1977).
Subjective norms have a positive and significant effect on continuance participation intentions, leading to continuance participation behaviour (Hajli, Shanmugam, Powell, \& Love, 2015). Subjective norms have been regarded as an important factor in the consumer's purchase intention by many theoretical and empirical studies (Amaro \& Duarte, 2015; Hasbullah, 2016; Khalil \& Michael, 2008). Hasbullah (2016) proved that young people were significantly influenced by attitudes, subjective norms and website usability in online shopping. Khalil and Michael (2008) determined that the subjective norms shaped by friends, family members, and colleagues positively influence individuals' online purchasing. Amaro and Duarte (2015) also proved that subjective norms significantly affect intentions to purchase travel offerings online. Therefore, subjective norms should be seen as an important factor in this study.

\section{Research Model and Hypotheses}

In the previous section, we identified five major constructs that are related to social commerce: mobile social commerce intention, social support, trust, perceived usefulness and subjective norms. The conceptual model of the current research is shown in Figure 1. It shows that social support affects perceived usefulness, trust and subjective norms. Trust is influenced by perceived usefulness and subjective norms and, in turn, trust, perceived usefulness and subjective norms affect the users' mobile social commerce intentions. The definitions and interrelationships of the factors in the conceptual model are listed in the following sections.

\section{I Social support}

Social support in this study is defined as online actions that individuals carry out by collaborating with peers through mobile social media. This can involve either providing assistance or seeking support (Barrera, 1986). Social support is the information that leads a person to believe that they are cared for, loved 
and respected as a member of a network of people that is built on mutual obligation (Liang et al., 2011). Social support is normally considered to be a multidimensional construct which has two dimensions in the online environment: emotional support and informational support (Chen \& Shen, 2015; Liang et al., 2011). Emotional support mainly concerns emotion, considering the feelings of other users, expressing sympathy, demonstrating understanding and making people feel valued. Informational support concerns the analysis of problems, the publication of people's insights or useful information, and assistance in solving problems and generating new ideas.

Users can find the information that they want on the social platform and they can communicate with others on the social platform to gain recognition and feel valued. The social platform meets the diverse needs of users so, for users, the emotional and informational support they receive leads them to perceive the platform as useful. Users are encouraged to trust products or services when they receive emotional and informational support that helps them to make purchasing decisions. Chen and Shen (2015) also argued that both emotional support and informational support have a significant effect on trust in the SC context. In general, when users encounter problems that require suggestions or opinions from others, they tend to seek help from friends and relatives around them, but in the era of mobile internet, users are more willing to seek help through social platforms. People on social platforms play an important role in users' decisions and the following hypotheses can therefore be posited:

H1: Social support has a positive effect on the user's perceived usefulness.

H2: Social support has a positive effect on the users' trust.

H3: Social support has a positive effect on the users' subjective norms.

\subsection{Subjective norms}

Subjective norms can be defined as the perceived social pressure from referent individuals or groups as to whether to perform or not to perform a particular action (Maochou, 2013). Subjective norms belong to the discipline of social psychology. From the psychological point of view, the behaviour and attitudes of the opinion leaders or the majority in the group will produce a psychological pressure on the individual and influence their behaviour. This psychological pressure is called the 'subjective norm'. In the online shopping environment, the influence of subjective norms on the consumers' purchase intentions is also confirmed by a large number of empirical studies. For example, Hsu's empirical investigations report that subjective norms positively influence behavioural intentions (Yu, Lee, \& Wu, 2005). Subjective norms have been found to be significantly related to intentions (Pavlou \& Chai, 2002). In addition, social networking sites are developing rapidly and the consumers are flooded with information and public opinions, which are more likely to be affected by the social environment. Therefore, in online communities, users experience intense exposure to others' opinions and are influenced by the overload of information provided by their significant others. Hence, this leads to the next hypotheses.

H4: Subjective norms have a positive effect on the users' trust.

H8: Subjective norms have a positive effect on the users' mobile social commerce intentions.

\subsection{Perceived usefulness}

Perceived usefulness is defined as the degree to which a person perceives that adopting MSC will boost his or her job performance (Davis, 1989). Based on a large number of empirical studies, perceived usefulness is an 
important factor affecting users' use intentions. For users, the purpose of social media platforms is to acquire information and knowledge and communicate with others. This perceived usefulness meets the needs of users and solves practical problems, prompting users to use the platform. Many authors have asserted that perceived usefulness affects users' intentions to use e-commerce (Gefen \& Straub, 2000; Lee, Park, \& Ahn, 2001). Yi (2016) also showed that perceived usefulness significantly positively influences online purchase intentions. This construct is applied in the current study to social commerce (Hajli, 2012). These authors found a significant positive effect of the perceived value of online connections on users' willingness to pay other members of social networking services (Han \& Windsor, 2011). In addition, when users perceive that the information provided by mobile social media platforms is useful, they will develop trust in mobile social commerce. Therefore, the following hypotheses are proposed:

H5: Perceived usefulness has a positive effect on the users' mobile social commerce intentions.

H6: Perceived usefulness has a positive effect on the users' trust.

\subsection{Trust}

The definition of trust in this article is the belief that one can rely upon a promise made by another and that the other, in unforeseen circumstances, will act toward oneself with goodwill and in a benign fashion in the MSC context (Suh \& Han, 2003). Online sales models tend to arouse distrust in buyers and sellers, so the effect of trust in e-commerce has been widely studied (Mutz, 2005). Many scholars have confirmed that trust plays an important role in the e-commerce adoption process (Aljifri, Pons, \& Collins, 2003). Hsiao, Lin, Wang, $\mathrm{Lu}$ and $\mathrm{Yu}$ (2010) also found that trust in product recommendations influences customers' purchase intentions. Accordingly, when customers trust product recommendations on social commerce sites, their intentions to purchase the recommended product are stimulated $(\mathrm{Li}, 2017)$. That is to say, the more trust the consumers have, the more likely it is that they will buy (Han $\&$ Windsor, 2011). Thus, we propose the following hypothesis:

H7: Trust has a positive effect on the users' mobile social commerce intentions.

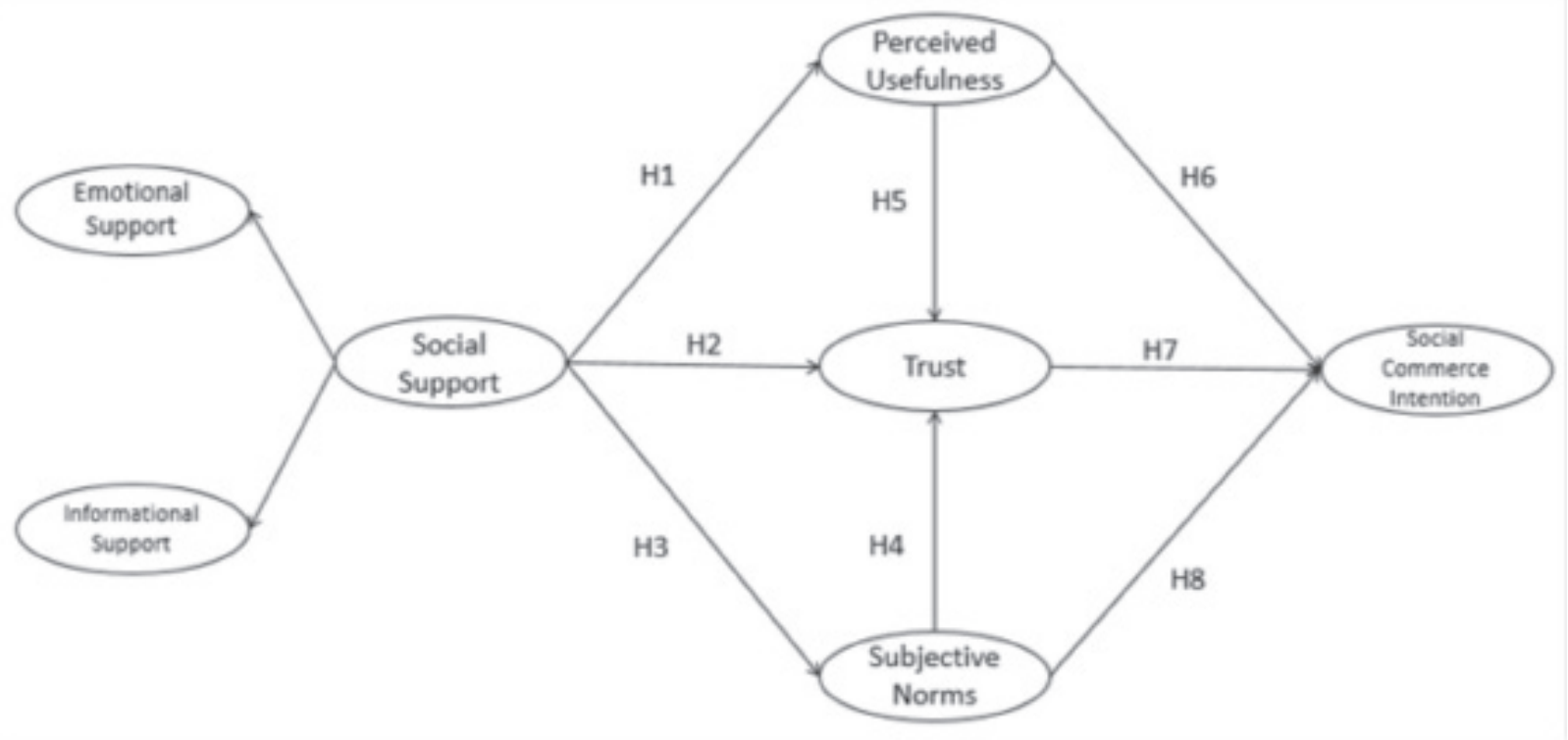

Figure 1. Research mode. 


\section{Research Methods}

\section{I Construct measurement}

Based on the previous studies, the research hypotheses and the conceptual model of this study underpin the empirical analysis of a valid sample of collected data to verify the influencing factors on people's willingness to use mobile social commerce. The study used SPSS and PLS software to analyse and process the data.

There are two parts to this survey: first, the demographic profiles of the respondents and, second, the items used to measure the constructs. Most of the items were adapted for the social commerce context from past research. The questionnaire used a Likert five point scale to measure the respondents' opinions, ranging from 'strongly disagree' to 'strongly agree'. 'Strongly disagree' was assigned 1 point; 'disagree', 2 points; 'neither agree nor disagree', 3 points; 'agree', 4 points; and 'strongly agree', 5 points. Table 1 provides a description of the variables involved in the study with their measurement dimensions, including social support, perceived usefulness, trust, subjective norms and social commerce intentions.

Table 1

\section{Summary of measurement scales}

\begin{tabular}{|c|c|c|}
\hline Item & Measure & Source \\
\hline & Emotional support (social support) & \\
\hline ES1 & When I am faced with difficulties, some people on Weibo are on my side. & \\
\hline ES2 & When I am faced with difficulties, some people on Weibo comfort and encourage me. & \\
\hline ES3 & When I am faced with difficulties, some people on Weibo listen to me talk about my private feelings. & (Liang et al., 2011) \\
\hline \multirow[t]{2}{*}{ ES4 } & $\begin{array}{l}\text { When I am faced with difficulties, some people on Weibo express interest and concern in my well- } \\
\text { being }\end{array}$ & \\
\hline & Information support (social support) & \\
\hline IS5 & On Weibo, some people offer suggestions when I need help. & \\
\hline IS6 & $\begin{array}{l}\text { When I encounter a problem, some people on Weibo give me information to help me overcome the } \\
\text { problem. }\end{array}$ & (Liang et al., 2011) \\
\hline \multirow[t]{2}{*}{ IS7 } & $\begin{array}{l}\text { When I am faced with difficulties, some people on Weibo help me to discover the cause and provide } \\
\text { me with suggestions. }\end{array}$ & \\
\hline & Perceived usefulness & \\
\hline PU1 & The method of obtaining useful shopping information through Weibo is efficient. & \\
\hline PU2 & The method of obtaining useful shopping information through Weibo is easy. & $\begin{array}{l}\text { (Sharma \& Crossler, } \\
\text { 2014) }\end{array}$ \\
\hline \multirow[t]{2}{*}{ PU3 } & The method of obtaining useful shopping information through Weibo is convenient. & \\
\hline & Trust & \\
\hline TR1 & I think that the product recommendations on this social commerce site are credible. & \\
\hline TR2 & I trust the product recommendations on this social commerce site. & (Hsiao et al., 2010) \\
\hline \multirow[t]{2}{*}{ TR3 } & I believe that the product recommendations on this social commerce site are trustworthy. & \\
\hline & Subjective norms & \\
\hline SN1 & My friends encouraged me to use Weibo. & \\
\hline $\mathrm{SN} 2$ & My colleagues encouraged me to use Weibo. & $\begin{array}{l}\text { (Dholakia, Bagozzi, } \\
\text { \& Pearo, 2004) }\end{array}$ \\
\hline \multirow[t]{2}{*}{ SN3 } & People around me encouraged me to use Weibo. & \\
\hline & Social commerce intention & \\
\hline SCI1 & I consider the shopping experiences of my friends on Weibo when I want to shop. & \\
\hline SCI2 & I ask my friends on Weibo to provide me with their suggestions before I go shopping. & (Hoili 2014 ) \\
\hline $\mathrm{SCI} 3$ & I am willing to buy products recommended by my friends on Weibo. & (Hajli, 2014a) \\
\hline SCI4 & I will consider shopping via Weibo when I want to shop. & \\
\hline
\end{tabular}




\subsection{Data collection and sampling technique}

This study takes a broad social population as the research subject and studies the willingness of various age groups to use mobile social commerce. Survey methods included questionnaires, field visits and random interviews. The questionnaire was our main survey method and we used an offline questionnaire method for our investigation. The questionnaire was distributed in the first half of 2017 and the distribution period lasted for approximately two months. In the pre-test phase of the questionnaire, we conducted face-to-face tests with students on campus and modified the flawed aspects of the questionnaire based on the test results to ensure that the meaning of each question was easily understood. After the preliminary tests, we distributed and collected questionnaires in high-traffic locations such as major shopping malls, plazas and residential buildings in Chengdu. Although the offline survey was time-consuming, its advantages were obvious. Because the people who collected the data and the people who filled out the questionnaire met face-to-face, the collection of false information was largely avoided. At the same time, the respondent could communicate with us during the completion of the offline questionnaire, thus avoiding the possibility of mistakes. Moreover, because the offline questionnaire was distributed randomly, people of different ages and occupations contributed their opinions to our research, whereas online questionnaires would have been more likely to focus on a certain group.

As Sina Weibo has a large number of users and is one of the largest mobile social platforms in China, this study takes Sina Weibo users as the target sample. A simple definition and example of the MSC were first explained to the target respondents, and they were then asked if they know or have any experience of MSC. If the answer was positive, then the respondents would be invited to answer the survey. A total of 300 people were invited to participate in the survey. We received 238 completed questionnaires (79\% response rate), scrutinized all responses, and dropped those with too much missing information. As a result, we obtained 207 valid responses.

\section{Results}

The research model shown in Figure 2 was analysed using the partial least squares structural equation modelling (PLS-SEM) method in Smart-PLS 3.0 (Hsu \& Lin, 2015; Ringle, Wende, $\&$ Will, 2005). PLS is suitable for studies with small sample sizes because it does not require multivariate normal distribution (Hew, Lee, Ooi, $\&$ Wei, 2015).

\section{I Demographic profiles}

Table 2 shows all the demographic variables for this study. According to the results of the questionnaire, the majority of respondents $57.27 \%$ - were male, while $42.73 \%$ were female. Most of the respondents were between 18 and 25 years old, accounting for $81.08 \%$ of the sample, which shows that the majority of people using MSC are young. This result is consistent with Weibo data (Weibo, 2018). This result indicates that young people are more willing to use mobile social commerce. In addition, students comprised $51.98 \%$ of the sample, accounting for half of all occupations, indicating that students have a stronger desire to try new things. 
Table 2

Demographic profiles of respondents

\begin{tabular}{lcc}
\hline Variables & Total & Percentage \\
\hline Gender & 119 & 57.27 \\
Male & 88 & 42.73 \\
Female & & \\
Age & 4 & 1.93 \\
Below 18 & 168 & 81.06 \\
$18-25$ & 29 & 14.1 \\
$26-30$ & 4 & 1.76 \\
$31-40$ & 2 & 0.97 \\
41 and above & & \\
Occupation & 108 & 51.96 \\
Student & 53 & 25.60 \\
Serving officers & 20 & 9.66 \\
Freelancer & 26 & 12.56 \\
Others & & \\
\hline
\end{tabular}

\subsection{Common method variance}

The concern for common method variance (CMV) arises when the responses for both the dependent and the explanatory variables are acquired from the same target respondent (Chang et al., 2010). In order to control the CMV, several remedial measures were carried out during the design and management of the questionnaire. These measures ensured the anonymity of respondents and that they fully understood the background of the questionnaire and the issues being investigated. The language used in the questionnaire was very simple and easy to understand, ensuring that respondents with different educational levels and ages could correctly understand the questions. In addition, after all the data were collected, the nonconforming questionnaires were deleted and deviations caused by the respondents who did not fill out the questionnaires were eliminated. In summary, the study was not greatly affected by the impact of CMV.

\section{$5 \cdot 3$ Inspecting the measurement model}

\subsection{Construct reliability of the measurement items}

The measurement model was assessed using PLS. The model was first evaluated in terms of reliability. Every survey construct includes items to assess internal consistency (Straub et al., 2004; Wasko \& Faraj, 2005) and different methods are used to test this internal consistency. Cronbach's alpha and composite reliability scores are two tools that are used to measure the reliability of research. In PLS it is advisable to calculate the composite reliability, the accepted value of which should exceed 0.70 and should be interpreted by Cronbach's alpha. If a construct has a value greater than 0.70 , it is considered to be an acceptable value for the test (Wasko \& Faraj, 2005). These two types of reliability test ensured that we could analyse the survey data accurately. As shown in Table 3, all measures exceeded the recommended thresholds, with composite reliability ranging from 0.943 to 0.963 and the Cronbach's alpha ranging from 0.910 to 0.951 . The data analysis results shown in Table 3 indicate that the questionnaire was very reliable and there was strong consistency across the variables. 
Table 3

Construct reliability of the measurement items

\begin{tabular}{|c|c|c|c|c|c|}
\hline Factors & Item & Standardized loading & AVE & Cronbach's alpha & Composite reliability \\
\hline \multirow{4}{*}{ ES } & ES1 & 0.912 & 0.841 & 0.937 & 0.954 \\
\hline & ES2 & 0.916 & & & \\
\hline & ES3 & 0.925 & & & \\
\hline & ES4 & 0.915 & & & \\
\hline \multirow{3}{*}{ IS } & IS1 & 0.950 & 0.914 & 0.953 & 0.969 \\
\hline & IS2 & 0.961 & & & \\
\hline & IS3 & 0.957 & & & \\
\hline \multirow{3}{*}{ PU } & PU1 & 0.939 & 0.890 & 0.938 & 0.960 \\
\hline & PU2 & 0.947 & & & \\
\hline & PU3 & 0.945 & & & \\
\hline \multirow{3}{*}{$\mathrm{TR}$} & TR1 & 0.954 & 0.898 & 0.943 & 0.963 \\
\hline & TR2 & 0.946 & & & \\
\hline & TR3 & 0.944 & & & \\
\hline \multirow{3}{*}{ SN } & SN1 & 0.890 & 0.848 & 0.910 & 0.943 \\
\hline & SN2 & 0.933 & & & \\
\hline & SN3 & 0.940 & & & \\
\hline \multirow{4}{*}{ SCI } & SCI1 & 0.910 & 0.867 & 0.948 & 0.963 \\
\hline & SCI2 & 0.944 & & & \\
\hline & SCI3 & 0.940 & & & \\
\hline & SCI4 & 0.941 & & & \\
\hline
\end{tabular}

\section{$5 \cdot 3 \cdot 2$ Construct validity of the measurement} items

A confirmatory factor analysis (CFA) can be used to measure the validity of a questionnaire, which includes convergent validity and discriminant validity. Convergent validity is established if items reflect their corresponding factors effectively, and discriminant validity is established if two factors are statistically different. Table 3 shows the standardised item loadings, the average variance extracted (AVE), and the composite reliability (CR). As shown in Table 3 , all item loadings were greater than 0.7. The T values showed that all loadings were significant at $\mathrm{p}<0.001$. All AVEs exceeded 0.5 and all CRs exceeded 0.7. Thus, the scale had good convergent validity (Gefen et al., 2000). To examine the discriminant validity, we compared the square root of the AVE and factor correlation coefficients. As shown in Table 4, the square root of the AVE was significantly larger than its correlation coefficient with other factors for each factor, so the scale had strong discriminant validity (Gefen et. al., 2000). In addition, the HTMT (heterotrait-monotrait) ratio was used. This measures correlations between pairs of constructs and should be around 0.85 (Henseler, Ringle, \& Sarstedt, 2015). As shown in Table 5, all HTMT ratios were less than 0.85, indicating that the resulting values were close to the limits recommended in the scientific literature. Table 4 and Table 5 show the factor loading for each construct and confirm that the observed indicators had sufficient convergent and discriminant validity. 
Table 4

The square root of AVE, factor correlation coefficients, and Q2

\begin{tabular}{lccccccc}
\hline & $\mathbf{Q}^{2}$ & ES & IS & PU & SCI & SN & TR \\
\hline ES & 0,663 & $\mathbf{0 , 9 1 7}$ & & & & & \\
IS & 0,704 & 0,775 & $\mathbf{0 , 9 5 6}$ & & & & \\
PU & 0,668 & 0,455 & 0,508 & $\mathbf{0 , 9 4 3}$ & & & \\
SCI & 0,701 & 0,546 & 0,543 & 0,673 & $\mathbf{0 , 9 3 1}$ & 0,931 & \\
SN & 0,488 & 0,506 & 0,513 & 0,560 & 0,612 & $\mathbf{0 , 9 3 6}$ & $\mathbf{0 , 9 4 7}$ \\
TR & 0,681 & 0,519 & 0,519 & 0,680 & 0,748 & 0,566 & \\
\hline
\end{tabular}

Table 5

The HTMT (heterotrait-monotrait) ratio

\begin{tabular}{lcccccc}
\hline & ES & SCI & IS & PU & SN & TR \\
\hline ES & & & & & & \\
SCI & 0,581 & & & & & \\
IS & 0,820 & 0,573 & & & & \\
PU & 0,486 & 0,713 & 0,538 & & & \\
SN & 0,616 & 0,687 & 0,613 & 0,666 & & \\
TR & 0,553 & 0,791 & 0,548 & 0,722 & 0,643 & \\
\hline
\end{tabular}

\subsection{Investigating the structural model}

Using the PLS algorithm and bootstrapping for repetitive sampling, a total of 207 cases with 2,000 repeated samplings were used to detect the structural model. The model test results included standardised path coefficients, t-test-based significance coefficients and decision coefficients $\left(\mathrm{R}^{2}\right)$. The results are shown in Figure 2. As shown in Figure 2, all hypotheses were supported in this study and the specific data is shown in Table 6 . Among the hypotheses, the relevance of social support to perceived usefulness, social support to subjective norms, perceived usefulness to trust, and trust to social commerce intention were significant at $\mathrm{p}<0.001$. The relevance of social support to trust, perceived usefulness to social commerce intention, and subjective norms to social commerce intention were significant at $\mathrm{p}<0.01$. The relevance of subjective norms to trust was significant at $\mathrm{p}<0.05$. The $\mathrm{f} 2$ effect measure was used to determine the size of the sequential multiple regressions. Following Cohen (1988), 0.02 represents a 'small' effect, 0.15 represents a 'medium' effect and 0.35 represents a 'high' effect. As shown in Table 6, all $\mathrm{f} 2$ values were greater than 0.02 , indicating that the relationships of SS to TR, SN to TR, PU to SCI, and SN to SCI had a small effect, PU to TR and TR to SCI had a medium effect, while SS to PU and SS to SN had a high effect. On this basis, we can say that the model had a high degree of predictive relevance with regard to the endogenous factors.

This result indicates that the proposed conceptual model had adequate explanatory significance (Farooq, Salam, Fayolle, Jaafar, \& Ayupp, 2018). As shown in Table 3, all Q2 values were larger than zero. This result shows that the endogenous factors (i.e., perceived usefulness, subject norms, trust and social commerce intentions) involved in this study had strong predictive relevance (Chin, 2010). The standardised root mean square residual (SRMR) value of this model was 0.058 (less than 0.08), indicating a very good model fit (Bentler, 1999; Wetzels, Odekerken-Schröder, \& Oppen, 2009).

Based on the above analysis, it was concluded that both the measurement model 
and the structural model were valid. Moreover, these results showed that the proposed theoretical model of this study had significant predictive relevance and explanatory power.

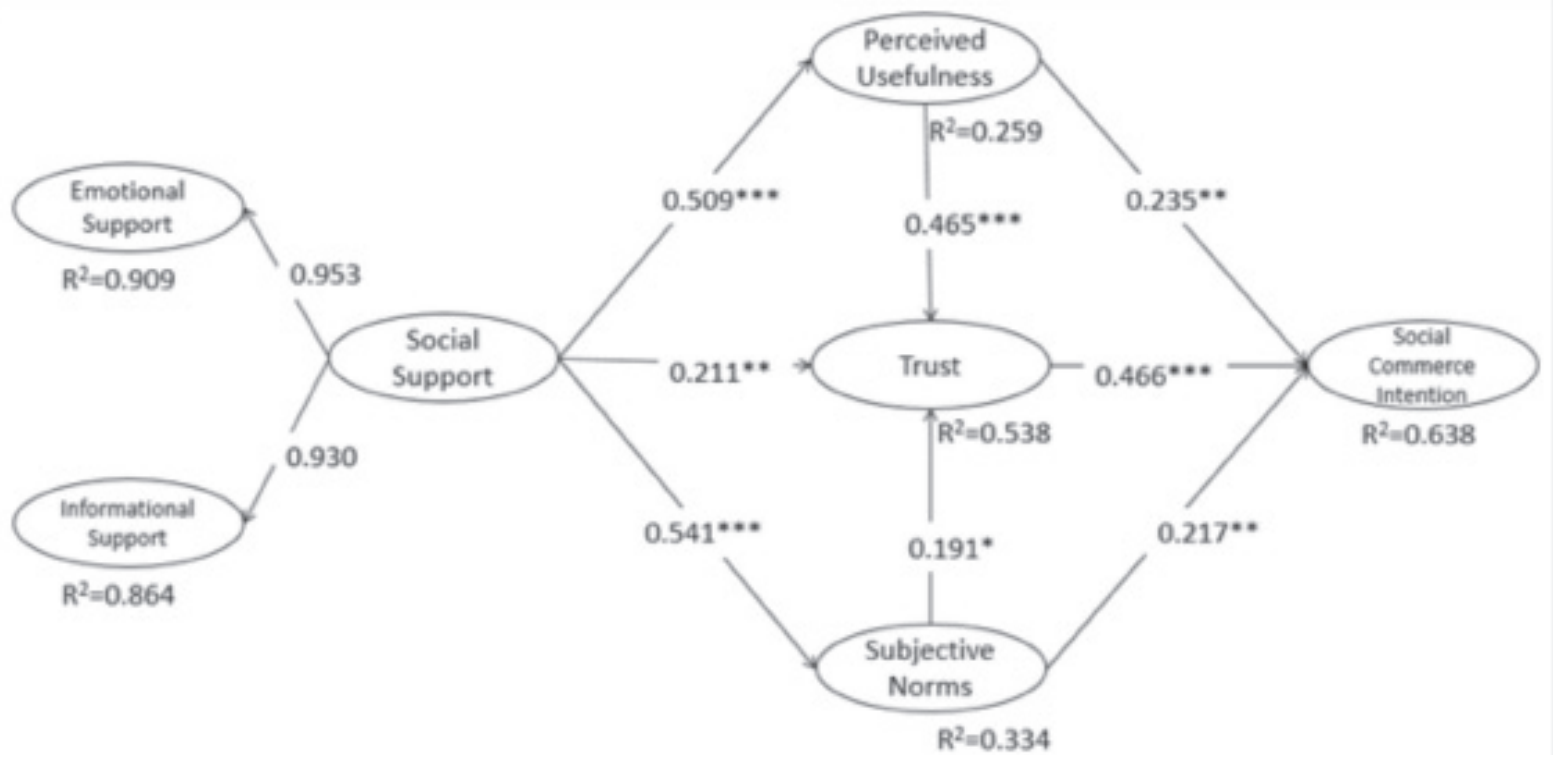

Figure 2. Results of the PLS analysis.

Table 6

\section{Results of the hypothesis testing}

\begin{tabular}{lcccccc}
\hline Hypotheses & Structural path & Correlation coefficient & T Statistics & P Statistics & Supported & f2 \\
\hline H1 & SS - > PU & 0,509 & 7,297 & 0,001 & Yes & 0,350 \\
H2 & SS- > TR & 0,211 & 2,832 & 0,01 & Yes & 0,059 \\
H3 & SS- > SN & 0,541 & 8,283 & 0,001 & Yes & 0,502 \\
H4 & SN- > TR & 0,191 & 2,345 & 0,05 & Yes & 0,039 \\
H5 & PU- > TR & 0,465 & 5,280 & 0,001 & Yes & 0,287 \\
H6 & PU- >SCI & 0,235 & 2,773 & 0,01 & Yes & 0,068 \\
H7 & TR- > SCI & 0,466 & 5,115 & 0,001 & Yes & 0,229 \\
H8 & SN->SCI & 0,217 & 2,788 & 0,01 & Yes & 0,077 \\
\hline
\end{tabular}

\section{Discussion}

The popularity of social media opens up a new platform for business and research opportunities. In this study, we propose an approach for explaining how trust from a social perspective affects users' social commerce. The approach involves four related constructs: social support, trust, perceived usefulness and subjective norms. These four constructs are grouped into three broad categories: social factors (i.e. social support, subjective norms), trust and perceived usefulness. We used Weibo as a suitable platform to empirically test our model of social commerce. Fundamentally, all the hypotheses ( $\mathrm{H} 1$ to $\mathrm{H} 8)$ in the model were supported by this study.

If users are able to obtain supportive information on mobile social commerce, they will be influenced by others and perceive mobile social commerce as useful, which will further affect their intentions to conduct mobile social commerce. The perceived usefulness and 
subjective norms of mobile social commerce affect trust in a positive manner and drive the purchase intentions. Furthermore, trust plays a significant role in developing continuance intentions. These results were expected and are consistent with Hajli (2012) and Hajli and Shanmugam (2015).

Among the factors affecting trust, perceived usefulness has the largest effect. If a platform cannot ensure usefulness, users may doubt the ability and integrity of the platform to provide them with quality mobile services, in turn decreasing their trust. We found that perceived usefulness and social support both have an effect on trust. This is consistent with Chen and Shen (2015), who established the effect of social support on trust. Users need to obtain accurate, relevant and up-to-date information in order to conduct mobile social commerce. If information is inaccurate or out-of-date, users may feel annoyed and experience a lack of control. In addition, an interesting finding of this study was that the impact of subjective norms was minimal. This suggests that users of the platform pay more attention to the usefulness and support information of the platform.

Compared with subjective norms and perceived usefulness, trust has the strongest effect on intentions to conduct mobile social commerce, which contradicts the findings of Tan et al. (2012). They discovered that the effect of perceived usefulness on intentions was stronger for the group with greater privacy concerns and explained that the decision of this group to use social networking sites mainly depended on perceived usefulness (Tan et al., 2012). However, our result supports the findings of Hajli (2013), Hajli (2015), Yahia, Al-Neama and Kerbache (2018). They explained that consumers feel close to each other on social media and encourage each other to have more participation on platforms, thus helping to alleviate problematic issues such as trust (Hajli, 2015; Yahia et al., 2018). Empirical tests significantly support the assertion that social commerce constructs increase trust. Therefore, platforms such as Facebook help to increase consumers' trust and intention to buy.

In summary, this study determined that, under the umbrella of social support, trust has the strongest influence on an individual's intention to engage in mobile social commerce, followed by perceived usefulness and subjective norms.

\section{Implications and Limitations}

\section{I Implications for researchers}

Overall, this study makes some important contributions to enrich the existing literature on user behaviour relating to MSC. First, this study reveals the mechanism of trust formation and actions in the MSC context. Trust plays an important role in users' adoption of MSC. This study confirms that social support, perceived usefulness, and subjective norms can motivate users' trust, in turn triggering users' intention to use MSC. Second, this study confirms the important role of social factors in user behaviour. Previous studies have seldom paid attention to the influence of social support and subjective norms on the MSC behaviour of users. This study indicates that social support (which includes emotional and informational support) and subjective norms have a positive impact on user trust. Third, this study expands social support theory. We confirm that there is a relationship between social support and subjective norms. Our results show that personal pressure comes not only from real society, but also from the virtual community. In addition, informational support and emotional support can enhance users' perception of the usefulness of MSC and help to build users' trust. Thus, our study enriches the literature on user behaviour relating to the adoption of MSC and provides an integrated framework for scholars who engage in similar research in the future.

\subsection{Implications for practitioners}

This study also has a certain value for companies that want to carry out mobile social business activities, offering some feasible 
suggestions for their business activities. First of all, our study found that social support influences trust, subjective norms, and perceived usefulness, so companies that intend to use MSC must provide plenty of social support, both emotionally and in terms of information, when the customer's shopping experience is unsatisfactory. At the same time, the information provided by companies on social media should be more detailed. Taking the Xiaomi mobile phone company as an example, in order to increase the users' willingness to purchase, the company could build a Weibo community, enabling users who have purchased Xiaomi mobile phone products to communicate with users who have not purchased the products but are willing to do so. This would make it easy for users to obtain information and emotional support in a timely manner. Second, because the willingness of users to shop via MSC is largely influenced by trust, companies should carefully study what the target groups for their products or services have in common with people concerned so that the target groups can pay attention to them. Enterprises should increase user trust in products through multiple channels, providing informational and emotional support. For example, monthly product and sales summaries can make users more aware of product information and the company could communicate with users using Weibo comments. Third, companies should grasp the importance of perceived usefulness. This makes it necessary, during the process of conducting business activities on social media, for the product information or shopping advice provided to users to be easily located, saving time and cost for users. For some digital products, merchants could provide services such as trial and test, thus enabling users to experience the product's usefulness and encouraging a purchase. Fourth, the users' willingness to buy is also influenced by subjective norms. Shopping advice that is important to the user will affect the user's willingness to purchase. For the promotion of products, companies should choose important people in the industry to advertise the features and benefits of the products. It is important to ascertain the preferences of the target users and develop appropriate marketing strategies.

\section{$7 \cdot 3$ Limitations and future research directions}

Of course, our research also has some limitations. First of all, because our research used only Weibo, mobile social business users of different platforms may have different purchase intentions. Secondly, when we conducted the questionnaire survey, our questionnaires were mainly completed by people in Chengdu, China, potentially restricting or skewing the composition of the sample population. Thirdly, we cannot guarantee that the respondents answered the questions truthfully. Hence, the questionnaires may have suffered from subjective factors.

Our research also has potential for further extension. Due to the limitations of the current research, the survey respondents were mainly mobile social business users in Chengdu, China. Future researchers could expand the geographic scope, making our research conclusions more generalisable. Additionally, different experimental methods could be used to reduce the influence of subjective factors on the respondents of the questionnaire.

\section{Acknowledgement}

We would like to express my gratitude to Prof. Zhigang Li, Dr. Shuaijiao Bai, and Dr. Xudong Chen for their help. This work was partially supported by grants from the Key Fund Project of the Research Center for Regional Public Management Informatization (QGXH18-09), the Key Fund Project of the Research Center for Sichuan County Economy Development (xy2017017) and the Project of Chengdu University of Technology Local Undergraduate College Students' Innovation and Entrepreneurship Education Research Base (YJ2017-JD002). 


\section{References}

Aljifri, H. A., Pons, A., \& Collins, D. (2003). Global e-commerce: A framework for understanding and overcoming the trust barrier. Information Management \& Computer Security, 11(3), 130-138.

Amaro, S., \& Duarte, P. (2015). An integrative model of consumers' intentions to purchase travel online. Tourism Management, 46, 64-79.

Ba, S., \& Pavlou, P. A. (2002). Evidence of the effect of trust building technology in electronic markets: price premiums and buyer behavior. Mis Quarterly, 26(3), 243-268.

Bai, Y., Yao, Z., \& Dou, Y. F. (2015). Effect of social commerce factors on user purchase behavior: An empirical investigation from renren.com. International Journal of Information Management, 35(5), 538-550. doi: 10.1016/j. ijinfomgt.2015.04.011

Barrera, M. B., Jr. (1986). Distinctions between social support concepts, measures, and models. American Journal of Community Psychology, 14(4), 413-445.

Bo, X. (2008). Multimodal computer-mediated communication and social support among older chinese internet users. Journal of Computermediated Communication, 13(3), 728-750.

Brown, S. A., Venkatesh, V., \& Bala, H. (2006). Household technology use: Integrating household life cycle and the model of adoption of technology in households. Journal The Information Society, 29(3), 205-218.

Chang, S. J., Witteloostuijn, A. V., \& Eden, L. (2010). From the Editors: Common method variance in international business research. Journal of International Business Studies, 41(2), 178-184.

Chen, J., \& Shen, X.-L. (2015). Consumers' decisions in social commerce context: An empirical investigation. Decision Support Systems, 79, 55-64. doi: 10.1016/j.dss.2015.07.012

Cheng, X., Gu, Y., \& Shen, J. (2019). An integrated view of particularized trust in social commerce: An empirical investigation. International Journal of Information Management, 45, 1-12. doi: 10.1016/j.ijinfomgt.2018.10.014

Chin, W. W. (2010). How to write up and report pls analyses. In V. Esposito Vinzi, W. W. Chin, J. Henseler, \& H. Wang (Eds.), Handbook of partial least squares: Concepts, methods and applications (pp. 655-690). Berlin, Heidelberg: Springer Berlin Heidelberg.

CNNIC. (2018). 42nd Statistical Report on the Development of Internet in China. http://www. cnnic.net.cn/hlwfzyj/hlwxzbg/hlwtjbg/201808/ t20180820_70488.htm

Cohen, J. (1988). Statistical Power Analysis for the Behavioral Sciences (2nd ed.). Hillsdale, NJ: Erlbaum.

Cook, K. S. (Ed.). (2001). Trust in society. NewYork, Russell Sage Foundation.

Curty, R. G., \& Zhang, P. (2011). Social commerce: Looking back and forward. Proceedings of the American Society for Information Science \& Technology, 48(1), 1-10.

Curty, R. G., \& Zhang, P. (2013). Website features that gave rise to social commerce: A historical analysis. Electronic Commerce Research \& Applications, 12(4), 260-279.

Davis, F. D. (1989). Perceived usefulness, perceived ease of use, and user acceptance of information technology. Mis Quarterly, 13(3), 319-340.

Dennison, G., Bourdage-Braun, S., \& Chetuparambi, M. (2009). Social commerce defined. Retrieved from https://digitalwellbeing. org/documents/IBM2009.pdf 
Dholakia, U. M., Bagozzi, R. P., \& Pearo, L. K. (2004). A social influence model of consumer participation in network- and small-group-based virtual communities. International Journal of Research in Marketing, 21(3), 241-263.

Dutot, V. (2015). Factors influencing Near Field Communication (NFC) adoption: An extended TAM approach. Journal of High Technology Management Research, 26(1), 45-57.

Eastin, M. S., \& Larose, R. (2005). Alt.support: Modeling social support online. Computers in Human Behavior, 21(6), 977-992.

Farooq, M. S., Salam, M., Fayolle, A., Jaafar, N., \& Ayupp, K. (2018). Impact of service quality on customer satisfaction in Malaysia airlines: A PLS-SEM approach. Journal of Air Transport Management, 67, 169-180.

Fishbein, M., \& Ajzen, I. (1977). Belief, attitude, intention and behaviour: An introduction to theory and research. Philosophy \& Rhetoric, 10(2), 130-132.

Gefen, D., \& Straub, D. W. (2000). The relative importance of perceived ease of use in is adoption: A study of e-commerce adoption. AIS Educator Journal, 1(8), 1-30.

Gefen, D., Straub, D. W., \& Boudreau, M. C. (2000). Structural equation modeling and regression: Guidelines for research practice. Communications of the Association for Information Systems, 4(7), 1-77.

Gibreel, O., AlOtaibi, D. A., \& Altmann, J. (2018). Social commerce development in emerging markets. Electronic Commerce Research and Applications, 27, 152-162. doi: 10.1016/j. elerap.2017.12.008

Giovannini, C. J., Ferreira, J. B., Silva, J. F. D., \& Ferreira, D. B. (2015). The effects of trust transference, mobile attributes and enjoyment on mobile trust. Bar Brazilian Administration Review, 12(1), 88-108.
Gottlieb, B. H., \& Bergen, A. E. (2010). Social support concepts and measures. Journal of Psychosomatic Research, 69(5), 511-520.

Gu, Z., Wei, J., \& Xu, F. (2015). An empirical study on factors influencing consumers" initial trust in wearable commerce. Journal of Computer Information Systems, 56(1), 79-85.

Hajli, M. (2012). Social commerce adoption model. Association for Information Systems, 3 -27.

Hajli, M. (2013). A research framework for social commerce adoption. Information Management \& Computer Security, 21(3), 144-154.

Hajli, M. N. (2014a). The role of social support on relationship quality and social commerce. Technological Forecasting and Social Change, 87, 17-27. doi: 10.1016/j.techfore.2014.05.012

Hajli, M. N. (2014b). A study of the impact of social media on consumers. International Journal of Market Research, 56(6), p. 388-404.

Hajli, N. (2015). Social commerce constructs and consumer's intention to buy. International Journal of Information Management, 35(2), 183-191. doi: 10.1016/j.ijinfomgt.2014.12.005

Hajli, N., Shanmugam, M., Powell, P., \& Love, P. E. D. (2015). A study on the continuance participation in on-line communities with social commerce perspective. Technological Forecasting and Social Change, 96, 232-241. doi: 10.1016/j. techfore.2015.03.014

Hajli, N., \& Sims, J. (2015). Social commerce: The transfer of power from sellers to buyers. Technological Forecasting and Social Change, 94, 350-358. doi: 10.1016/j.techfore.2015.01.012

Hajli, N., Sims, J., Zadeh, A. H., \& Richard, M. O. (2017). A social commerce investigation of the role of trust in a social networking site on purchase intentions. Journal of Business Research, 71, 133-141. doi: 10.1016/j.jbusres.2016.10.004

Han, B., \& Windsor, J. (2011). User"s willingness to pay on social network sites. Journal of Computer Information Systems, 51(4), 31-40. 
Hasbullah, N. A., Osman, A., Abdullah, S., Salahuddin, S. N., Ramlee, N. F., \& Soha, H. M. (2016). The relationship of attitude, subjective norm and website usability on consumer intention to purchase online: An evidence of Malaysian youth . Procedia Economics and Finance, 35, 493-502.

Henseler, J., Ringle, C. M., \& Sarstedt, M. (2015). A new criterion for assessing discriminant validity in variance-based structural equation modeling. Journal of the Academy of Marketing Science, 43(1), 115-135.

Hew, J.-J., Lee, V.-H., Ooi, K.-B., \& Lin, B. (2016). Mobile social commerce: The booster for brand loyalty? Computers in Human Behavior, 59, 142-154. doi: 10.1016/j.chb.2016.01.027

Hew, J. J., Lee, V. H., Ooi, K. B., \& Wei, J. (2015). What catalyses mobile apps usage intention: an empirical analysis. Industrial Management \& Data Systems, 115(7), 1269-1291.

Hill, R. J. (1975). Belief, attitude, intention and behavior: an introduction to theory and research. by Martin Fishbein; Icek Ajzen. Philosophy \& Rhetoric, 41(4), 842-844.

House, J. S. (1981). Work stress and social support. Reading, Massachusetts: Addison-Wesley. Retrieved from https://www.worldcat.org/title/ work-stress-and-social-support/oclc/654126161

Hsiao, K. L., Lin, J. C. C., Wang, X. Y., Lu, H. P., $\& \mathrm{Yu}, \mathrm{H}$. (2010). Antecedents and consequences of trust in online product recommendations. Online Information Review, 34(6), 935-953.

Hsu, C. L., \& Lin, C. C. (2015). What drives purchase intention for paid mobile apps? - An expectation confirmation model with perceived value. Electronic Commerce Research \& Applications, 14(1), 46-57.

Huang, K. Y., Nambisan, P., \& Uzuner, Ö. (2010). Informational support or emotional support: preliminary study of an automated approach to analyze online support community contents. International Conference on Information Systems, 1-11.

Hu, L., \& Bentler, P. M. (1999). Cutoff criteria for fit indexes in covariance structure analysis: Conventional criteria versus new alternatives. Structural Equation Modeling, 6(1), 1-55.

iMedia Research. (2017). China Mobile Social User Insight Report 2017. https://www.iresearch. com.cn $/$ Detail $/$ report $?$ id $=3020 \&$ isfree $=0$

Jarvenpaa, S. L., Tractinsky, N., \& Vitale, M. (1999). Consumer trust in an Internet store. Information Technology and Management, 1(1-2), 45-71.

Kang, J. Y. M., \& Johnson, K. K. P. (2015). F-commerce platform for apparel online social shopping: Testing a Mowen's 3M model: International Journal of Information Management, 35(6), 694-701.

Kaplan, A. M. (2012). If you love something, let it go mobile: Mobile marketing and mobile social media 4x4. Business Horizons, 55(2), 129-139.

Kim, C., Mirusmonov, M., \& Lee, I. (2010). An empirical examination of factors influencing the intention to use mobile payment. Computers in Human Behavior, 26(3), 310-322.

Kim, S., \& Park, H. (2013). Effects of various characteristics of social commerce (s-commerce) on consumers' trust and trust performance. International Journal of Information Management, 33(2), 318-332.

Kucukcay, I. E., \& Benyoucef, M. (2014). Mobile social commerce implementation. Proceeding (pp. 1-8). New York, NY, US: ACM. doi.10.1145/2668260.2668276

Lee, D., Park, J., \& Ahn, J. (2001). On the Explanation of Factors Affecting E-Commerce Adoption. International Conference of Information Systems, 14. Retrieved from https://pdfs. semanticscholar.org/4326/3ddab88f2fa258c8c4 8 e6c66c7f13a5ba3ef.pdf 
Li, C.-Y. (2017). How social commerce constructs influence customers' social shopping intention? An empirical study of a social commerce website. Technological Forecasting and Social Change. 144, 282-294. doi: 10.1016/j.techfore.2017.11.026

Liang, T., Ho, Y., Li, Y., \& Turban, E. (2011). What drives social commerce: the role of social support and relationship quality. International Journal of Electronic Commerce, 16(2), 69-90.

Lin, H. F. (2011). An empirical investigation of mobile banking adoption: The effect of innovation attributes and knowledge-based trust. International Journal of Information Management, 31(3), 252-260.

Lu, B., Fan, W., \& Zhou, M. (2016). Social presence, trust, and social commerce purchase intention: An empirical research. Computers in Human Behavior, 56, 225-237. doi: 10.1016/j. chb.2015.11.057

Madjar, N. (2011). Emotional and informational support from different sources and employee creativity. Journal of Occupational \& Organizational Psychology, 81(1), 83-100.

Maochou, H. (2013). The management of sports tourism: A causal modeling test of the theory of planned behaviour. International Journal of Management, 30(2), 474-491.

Mcknight, D. H., Choudhury, V., \& Kacmar, C. (2002). The impact of initial consumer trust on intentions to transact with a web site: A trust building model. Journal of Strategic Information Systems, 11(3), 297-323.

Molinillo, S., Liébana-Cabanillas, F., \& AnayaSánchez, R. (2018). A social commerce intention model for traditional e-commerce sites. Journal of theoretical and applied electronic commerce research, 13(2), 80-93. doi: 10.4067/s071818762018000200107

Mutz, D. C. (2005). Social trust and e-commerce: Experimental evidence for the effects of social trust on individuals' economic behavior. Public Opinion Quarterly, 69(3), 393-416.
Nor, K. M., PEARSON, \& Michael, J. (2008). An Exploratory Study Into the Adoption of Internet Banking in a Developing Country: Malaysia. Journal of Internet Commerce, 7(1), 29-73.

Obst, P., \& Stafurik, J. (2010). Online we are all able bodied: Online psychological sense of community and social support found through membership of disability-specific websites promotes well-being for people living with a physical disability. Journal of Community \& Applied Social Psychology, 20(6), 525-531.

Pavlou, P. A., \& Chai, L. (2002). What drives electronic commerce across cultures? Acrosscultural empirical investigation of the theory of planned behavior. Journal of Electronic Commerce Research, 3(4), 240-253.

Paxton, P. (1999). Is social capital declining in the united states? A multiple indicator assessment. American Journal of Sociology, 105(1), 88-127.

Ridings, C. M., \& Gefen, D. (2004). Virtual community attraction: Why people hang out online. Journal of Computer-mediated Communication, 10(1), 00-00. doi: https://doi. org/10.1111/j.1083-6101.2004.tb00229.x

Ringle, C., Wende, S., \& Will, A. (2005). SmartPLS 2.0 M3 Beta. Hamburg: University of Hamburg.

Sharma, S., \& Crossler, R. E. (2014). Disclosing too much? Situational factors affecting information disclosure in social commerce environment. Electronic Commerce Research and Applications, 13(5), 305-319. doi: 10.1016/j. elerap.2014.06.007

Shaw, L. H., \& Gant, L. M. (2002). In defense of the internet: The relationship between Internet communication and depression, loneliness, self-esteem, and perceived social support. 5(2), 157-71.

Sheikh, Z., Islam, T., Rana, S., Hameed, Z., \& Saeed, U. (2017). Acceptance of social commerce framework in Saudi Arabia. Telematics and 
Informatics, 34(8), 1693-1708. doi: 10.1016/j. tele.2017.08.003

Shi, S., \& Chow, W. S. (2015). Trust development and transfer in social commerce: Prior experience as moderator. Industrial Management \& Data Systems, 115(7), 1182-1203.

Straub, D., Boudreau, M. C., \& Gefen, D. (2004). Validation guidelines for IS positivist research. Communications of the Association for Information Systems, 13, 380-427

Suh, B., \& Han, I. (2003). The impact of customer trust and perception of security control on the acceptance of electronic commerce. International Journal of Electronic Commerce, 7(3), 135-161.

Tan, W. H., Ooi, K. B., Chong, S. C., \& Hew, T. S. (2014). NFC mobile credit card: The next frontier of mobile payment? Telematics \& Informatics, 31(2), 292-307.

Tan, X., Qin, L., Kim, Y. , \& Hsu, J. (2012). Impact of privacy concern in social networking web sites. Internet Research, 22(2), 211-233.

Taylor, S. E., Sherman, D. K., Kim, H. S., Jarcho, J., Takagi, K., \& Dunagan, M. S. (2004). Culture and social support: Who seeks it and why? Journal of Personality and Social Psychology, 87(3), 354362.

Warren, M. E., \& Abbott, P. (Ed). (1999). Democracy and Trust. Cambridge University Press.

Wasko, M. L., \& Faraj, S. (2005). Why should I share? Examining social capital and knowledge contribution in electronic networks of practice. Mis Quarterly, 29(1), 35-57.

Weibo. (2018). White paper on weibo and e-commerce in 2018. http://data.weibo.com/ report $/$ reportDetail?id $=423$

Wetzels, M., Odekerken-Schröder, G., \& Oppen, C. V. (2009). Using PLS Path Modeling for Assessing Hierarchical Construct Models: Guidelines and Empirical Illustration. Mis Quarterly, 33(1), 177-195.

Yahia, I. B., Al-Neama, N., \& Kerbache, L. (2018). Investigating the drivers for social commerce in social media platforms: Importance of trust, social support and the platform perceived usage. Journal of Retailing \& Consumer Services, 41, 11-19.

Yi, J. L., Osman, A., Salahuddin, S. N., Romle, A. R., \& Abdullah, S. (2016). Factors influencing online shopping behavior: The mediating role of purchase intention. Procedia Economics \& Finance, 35, 401-410.

Yu, T. \& Lee, N. \& Wu, G.. (2005). An empirical research of Kinmen tourists' behavioral tendencies model - A case of cross-validation in causal modeling. Journal of Tourism Studies, 11, 355-384.

Zhang, K. Z. K., Benyoucef, M., \& Zhao, S. J. (2016). Building brand loyalty in social commerce: The case of brand microblogs. Electronic Commerce Research \& Applications, 15, 14-25.

Zhou, L., Zhang, P., \& Zimmermann, H. D. (2013). Social commerce research: An integrated view. Electronic Commerce Research \& Applications, 12(2), 61-68.

Zhou, T. (2014a). An empirical examination of initial trust in mobile payment. Wireless Personal Communications, 77(2), 1519-1531.

Zhou, T. (2014b). Understanding the determinants of mobile payment continuance usage. Industrial Management \& Data Systems, 114(6), 936-948.

Zhou, T., \& Li, H. (2014). Understanding mobile SNS continuance usage in China from the perspectives of social influence and privacy concern. Industrial Management \& Data Systems, 37, 283-289. 


\section{Supporting Agencies:}

1. The Key Fund Project of the Research Center for Regional Public Management Informatization (QGXH18-09).

2. The Key Fund Project of the Research Center for Sichuan County Economy Development (xy2017017).

3. The Project of Chengdu University of Technology Local Undergraduate College Students' Innovation and Entrepreneurship Education Research Base (YJ2017-JD002).

\section{Authors:}

1. Yong Liu, PhD Student in Management Science and Engineering, Chengdu University of Technology, Chengdu, China. Email:523849711@qq.com

ORCID

(iD) 0000-0001-9550-2027

2. Fu Cui, Undergraduate in E-commerce, Chengdu University of Technology, Chengdu, China. Email:1252239356@qq.com

\section{ORCID}

(iD) 0000-0002-6587-6615

3. Xiaowei Su, Undergraduate in E-commerce, Chengdu University of Technology, Chengdu, China. Email:1049590379@qq.com

ORCID

(D) 0000-0001-9624-8948

4. Xiaojing Du, Undergraduate in E-commerce, Chengdu University of Technology, Chengdu, China. Email:1195048605@qq.com

ORCID

(D) 0000-0002-0835-5290

\section{Contribution of each author}

\begin{tabular}{lcccc}
\hline Contribution & Yong Liu & Fu Cui & Xiaowei Su & Xiaojing Du \\
\hline 1. Definition of research problem & $\sqrt{ }$ & & & \\
2. Development of hypotheses or research questions & $\sqrt{ }$ & & $\sqrt{ }$ & \\
(empirical studies) & $\sqrt{ }$ & & $\sqrt{ }$ & \\
3. Development of theoretical propositions (theoretical work) & $\sqrt{ }$ & $\sqrt{ }$ & $\sqrt{ }$ \\
4. Theoretical foundation/ Literature review & $\sqrt{ }$ & $\sqrt{ }$ & $\sqrt{ }$ \\
5. Definition of methodological procedures & & $\sqrt{ }$ & $\sqrt{ }$ \\
6. Data collection & & $\sqrt{ }$ & $\sqrt{ }$ \\
7. Statistical analysis & $\sqrt{ }$ & $\sqrt{ }$ & $\sqrt{ }$ & $\sqrt{ }$ \\
8. Analysis and interpretation of data & $\sqrt{ }$ & $\sqrt{ }$ & $\sqrt{ }$ \\
9. Critical revision of the manuscript & & & & \\
10. Manuscript writing & & & \\
11. Other (please specify which) &
\end{tabular}

\section{Erratum}

Where was written:

"Review of Business Management, São Paulo, v.21, n.5, p.839-860, oct/dec. 2019."

Now read:

“Rev. Bras. Gest. Neg. São Paulo v.21 n.4 oct-dec. 2019 p. 839-860” 